\title{
Parametrial Fat Tissue from High Fat Diet-Treated SKH-1 Mice Stimulates Transformation of Mouse Epidermal JB6 Cells
}

\author{
Jamie J. Bernard'1, You-Rong Lou', Qing-Yun Peng1', Tao Li'1, Priyal R. Vakil', Ning Ding', Jeffrey D. Laskin², Zigang Dong ${ }^{3}$, Allan H. \\ Conney ${ }^{1 \#}$, and Yao-Ping Lu' ${ }^{1 *}$
}

${ }^{1}$ Susan Lehman Cullman Laboratory for Cancer Research, Department of Chemical Biology, Ernest Mario School of Pharmacy, Rutgers, The State University of New Jersey, Piscataway, New Jersey, USA

${ }^{2}$ Department of Environmental and Occupational Medicine, University of Medicine and Dentistry of New Jersey-Roert Wood Johnson Medical School, New Jersey, USA

${ }^{3}$ The Hormel Institute, University of Minnesota, Austin, USA

\#Deceased

\begin{abstract}
Our previous studies indicated that decreasing visceral adipose tissue by surgical removal of the parametrial fat pads inhibited UVB-induced carcinogenesis in SKH-1 mice fed a high fat diet (HFD), but not a low fat diet (LFD) indicating that the parametrial fat tissue from mice fed a HFD played a role in skin carcinogenesis.

Objective: In the present study, we sought to investigate how a HFD may influence the intrinsic properties of the parametrial fat tissue to influence UVB-induced skin tumor formation.

Methods and Results: Immunohistochemical staining, adipokine array, and flow cytometry showed that parametrial fat tissue from mice fed a HFD had a higher density of macrophage-fused dead adipocytes (crownlike structures), more adipokines, and stimulated the production of more reactive oxygen species compared with parametrial fat tissue from mice fed a LFD. These differences between parametrial fat tissue from mice fed a HFD and LFD were associated with their effect on the in vitro transformation of mouse epidermal JB6 cells. Our results indicated that fat tissue filtrate (an aqueous filtrate made from the parametrial fat pad) from mice fed a HFD enhanced the conversion of JB6 cells from an epithelial-like morphology to cells with a fibroblast-like morphology to a greater extent than fat tissue filtrate from mice fed a LFD. Studies indicated that the fibroblast-like cells had decreased levels of E-cadherin, increased levels of Twist as assayed by western blot. Fat tissue filtrate made from the parametrial fat tissue of mice fed a HFD had $160 \%$ more transforming activity than that from mice fed a LFD and formed malignant mesenchymal tumors in vivo.
\end{abstract}

Conclusion: These studies provide the first in vitro demonstration of a parametrial fat tissue-induced transformation of an epidermal cell.

Keywords: High fat diet; Parametrial fat tissue;JB6 cell transformation

Abbreviations: LFD: Low Fat Diet; HFD: High Fat Diet; MEM: Minimum Essential Medium; FBS: Fetal Bovine Serum

\section{Introduction}

Non-melanoma skin cancer is the most common neoplasm in the United States with over 2 million new cases diagnosed per year caused predominantly by exposure to UVA and UVB in sunlight, the most prevalent environmental carcinogen [1]. Epidemiological studies indicate that high fat diets are associated with an increased risk of non-melanoma skin cancer, and patients who reduce their intake of calories from fat have a reduced reoccurrence of prior actinic keratosis and non-melanoma skin cancers [2,3]. Our previous research demonstrated that feeding a high fat diet to SKH-1 mice enhanced UVB-induced skin cancer [4,5] and that reducing parametrial fat tissue (visceral fat around the uterus) by caffeine administration, voluntary exercise or directly removal of the parametrial fat pad by surgical procedure inhibited UVB-induced skin tumor formation [69]. Interestingly, decreasing visceral adipose tissue by surgical removal of the parametrial fat pads inhibited UVB-induced carcinogenesis in SKH-1 mice fed a high fat diet (HFD), but not a low fat diet (LFD) indicating that the parametrial fat tissue from mice fed a HFD played a role in skin carcinogenesis. These data suggested that the parametrial fat tissue from mice fed a HFD secretes tumorigenic substances that promote skin tumor formation. Next, we sought to investigate how a HFD may influence the intrinsic properties of the parametrial fat tissue to influence UVB-induced skin tumor formation. As the mouse Balb/C epidermal JB6 P+ cell line has been utilized as a well-characterized in vitro model for neoplastic transformation by tumor promoters such as 12-O-tetradecanoylphorbol-13-acetate (TPA) [10], to determine the differences between visceral fat tissue from mice fed either a HFD or LFD in carcinogenesis, we tested the effect of an aqueous filtrate made from parametrial fat tissue on the in vitro transformation of JB6 epidermal cells.

\section{Methodology}

\section{Animals, parametrial fat pad isolation and diet}

Female SKH-1 hairless mice (6-7 weeks old) were purchased from Charles River Breeding Laboratories. Mice (six per group) were fed the low fat chow or high fat diets for 4 months prior to performing

*Corresponding author: Dr. Yao-Ping Lu, Susan Lehman Cullman Laboratory for Cancer Research, Department of Chemical Biology, Ernest Mario School of Pharmacy, Rutgers, The State University of New Jersey, 164 Frelinghuysen Rd., Piscataway, NJ 08854, USA, Tel: (848)-445-8004; E-mail: yaoping.lu@pharmacy.rutgers.edu

Received May 15, 2014; Accepted July 29, 2014; Published July 31, 2014

Citation: Bernard JJ, Lou YR, Peng QY, Li T, Vakil PR, et al. (2014) Parametrial Fat Tissue from High Fat Diet-Treated SKH-1 Mice Stimulates Transformation of Mouse Epidermal JB6 Cells. J Carcinog Mutagen 5: 183. doi:10.4172/21572518.1000183

Copyright: (C) 2014 Bernard JJ, et al. This is an open-access article distributed under the terms of the Creative Commons Attribution License, which permits unrestricted use, distribution, and reproduction in any medium, provided the original author and source are credited. 
parametrial fat pad isolation by sterile technique as described previously [7]. Isolated parametrial fat pads were weighed and placed in a sterilized tube for future use. The $13.5 \% \mathrm{kcal}$ Purina laboratory chow $5001 \mathrm{chow}$ diet was purchased from the Ralston Purina Co. (St. Louis, MO). The $60 \%$ kcal high fat diet is AIN 76A modified Rodent OpenSource Diet and purchased from Research Diets, Inc. (New Brunswick, NJ). This diet contains $34.9 \%$ fat by weight, and $54.4 \%$ of the total calories come from lard as described in [11].

\section{Measurement of crown-like structures (CLS) by immunohistochemistry}

Parametrial fat tissue was dissected and fixed in $10 \%$ buffer-formalin overnight at room temperature and embedded in paraffin. Four micron-thick sections were cut, deparaffinized in xylene, rehydrated in a graded ethanol series, and used for staining. Immunohistochemical staining was performed using a standard protocol. Serial sections were microwave-treated in $10 \mathrm{mmol} / \mathrm{l}$ citrate buffer $(\mathrm{pH}$ 6.0) and then incubated for $1 \mathrm{~h}$ at room temperature with primary antibodies, mouse monoclonal F4/80 (Abcam, Cambridge, MA). After rinsing in PBS buffer containing $0.25 \%$ Triton X-100 ( $\mathrm{pH} 7.2$ ), sections were incubated with secondary biotinylated goat anti-mouse (Abcam) antibodies. Avidin-biotin peroxidase complexes (Vector Laboratories, Burlingame, CA) were added followed by visualization with $3.3^{\prime}$-diaminobenzidine tetrachloride (Vector). All sections were counterstained with Harris hematoxylin. For each sample, the numbers of crown-like structures within the entire section were counted by two independent observers using a light microscope and normalized for the total section area as expressed as CLS per $\mathrm{mm}^{2}$ of tissue section.

\section{Preparation of fortified minimum essential medium and protein measurements}

A homogenate of the parametrial fat tissue was placed in a Millicell hanging polyethylene terephthalate insert (a 15-mm wide insert that has $0.4 \mu \mathrm{m}$ pores which permitted the diffusion of small molecules pass through into the medium) and placed in $1 \mathrm{~mL}$ of minimal essential medium (MEM) (phenol-red free) to make MEM fortified with an aqueous filtrate of the parametrial fat pads. This method allowed the minimization of lipid diffusion and the enrichment of protein. Homogenized fat tissue was made using the Qiagen TissueRuptor on medium speed at $10 \mathrm{sec}$ per $100 \mathrm{mg}$ fat tissue. Substances as well as other fat tissue constituents passed through the $0.4 \mu \mathrm{m}$ pores membrane of the insert into the medium were collected. Protein concentration in fortified medium was quantified using the Thermo Scientific ${ }^{\mathrm{Tw}}$ Pierce ${ }^{\mathrm{Tw}}$ BCA Protein Assay kit.

\section{Adipokine array}

Measurement of mouse adipokines (detection of 38 adipokines) from fat tissue filtrates was performed using the Mouse Adipopkine Antibody Array kit (purchased from R\&D Systems) as previously described [7]. Briefly, membranes were treated with $2 \mathrm{~mL}$ of blocking buffer and then incubated overnight with $1 \mathrm{~mL}$ of fat tissue filtrates containing $150 \mu \mathrm{g}$ protein at $4^{\circ} \mathrm{C}$. After washing, $1 \mathrm{~mL}$ of a mixture of biotinconjugated antibodies that are specific to the different targets on the array were added for $1 \mathrm{~h}$ and then incubated with $2 \mathrm{~mL}$ of HRPconjugated streptavidin at room temperature for $2 \mathrm{~h}$. The membranes were then treated with $500 \mu \mathrm{L}$ of detection buffer for 2 min and, finally, exposed to X-ray film using film developer. By comparing the signal intensities, relative expression levels of cytokines were determined and quantified by densitometry using Image $\mathrm{J}$ software. Positive controls were used to normalize the results. Adipokine array was performed at least 3 times for each treatment group.

\section{Cell culture and reagents}

JB6 P+ cells (Cl 41-5a; JB6 cells) were obtained from the American Type Culture Collection (Manassas, VA). The JB6 cells were cultured in monolayers at $37^{\circ} \mathrm{C}, 5 \% \mathrm{CO}_{2}$ with Eagle's minimal essential medium (MEM) (Sigma) containing 5\% fetal bovine serum (FBS) (Sigma), 2 $\mathrm{mM}$ L-glutamine, penicillin 100 (units/mL) and streptomycin $(100 \mu \mathrm{g} /$ $\mathrm{mL}$ ). Difco Agar was purchased from Becton Dickson and Company (Franklin Lakes, NJ).

\section{Measurement of reactive oxygen species by flow cytometry}

JB6 cells (70\% confluent) were treated with fat tissue filtrate (50 $\mu$ g protein $/ \mathrm{mL}), 5 \% \mathrm{FBS}$, or TPA $(10 \mathrm{ng} / \mathrm{mL})$ with $5 \% \mathrm{FBS}$ for $1,4,8$, 24 and 48 hours, respectively. During the last 30 minutes of culture, cells were incubated with $10 \mu \mathrm{M} 2^{\prime}, 7^{\prime}$-dichlorodihydrofluorescein diacetate (H2DCF-DA) at $37^{\circ} \mathrm{C}$. Cells were then washed with PBS, trypsinized and resuspended in PBS for measurement of fluorescence on a Beckman Coulter FC500 flow cytometer. The conversion of dichlorodihydrofluorescein (H2DCF-DA; non-fluorescent) to $2^{\prime}, 7^{\prime}$-dichlorofluorescein (DCF; fluorescent) detects a broad range of oxidants, including superoxide, peroxynitrate, hydrogen peroxide, and nitric oxide (NO). Mean fluorescence intensity of the 2', 7'-dichlorofluorescein (DCF) of 5,000 events was calculated.

\section{JB6 cell proliferation and transformation}

JB6 cells were seeded at 100 cells per well of a 6-well plate in $1 \mathrm{ml}$ of MEM containing 5\% FBS. 24 hours later, the medium was removed and fresh MEM containing fat tissue filtrate only (without FBS) was added. JB6 cells were cultured for 7 days, washed with 5\% PBS and fixed in $90 \%$ ice cold ethanol for 10 minutes. Clones were stained with Giemsa solution for 10 minutes, air-dried and counted. Clone morphology was analyzed by light microscopy.

Following a 7 day culture of JB6 cells treated with fat tissue filtrate (50 $\mu \mathrm{g}$ protein $/ \mathrm{mL}$ ) alone or with 5\% FBS as a control, 104 cells in 1.5 $\mathrm{mL}$ of $0.33 \%$ Difco Agar in MEM containing 5\% FBS were plated over 7 $\mathrm{mL}$ of $0.5 \%$ Difco Agar in MEM containing 10\% FBS in $60 \mathrm{~mm}$ dishes. The cultures were maintained at $37^{\circ} \mathrm{C}$ in a $5 \% \mathrm{CO}_{2}$ incubator for 14 days. Cell colonies that grew on soft agar were scored by counting the number of colonies with 8 or more cells in a 40 -fold light microscopic magnification.

\section{Western blotting analysis}

Cells (105) were incubated with $50 \mu \mathrm{L}$ lysis buffer supplemented with phenylmethanesulfonylfluoride on ice. Samples were clarified by centrifugation at $22,000 \times \mathrm{g}$ for $5 \mathrm{~min}$ at $4^{\circ} \mathrm{C}$. Lysates containing equal amounts of total protein $(20 \mu \mathrm{g})$ were separated in Bio-Rad mini Protean gels (Hercules, CA). Gels were run and transferred onto polyvinylidene difluoride transfer membranes (Millipore, Bedford, MA). Membranes were blocked with the Odyssey infrared imaging system blocking buffer (LI-COR, Lincoln, NE) probed with primary antibodies to E-cadherin (ab53033; 1:500) or Twist (ab50887; 1:50), purchased from Abcam, Cambridge, MA, overnight at $4^{\circ} \mathrm{C}$. Membranes were washed and incubated with goat anti-rabbit IRDye 800 (Rockland Immunochemicals, Gilbertsville, PA) or goat anti-mouse IRDye 680 Infrared (Li-COR) for $30 \mathrm{~min}$ at room temperature. Membranes were washed and fluorescence was detected using the Odyssey infrared imaging system (LI-COR).

Statistical analysis: Student's t tests (unpaired, two-tailed) were used to determine differences between treatments using Microsoft 
Excel. The data were expressed as the mean \pm SEM. Differences were considered significant at $\mathrm{P}<0.05$.

\section{Results}

Cellular and molecular differences between HFD and LFD fat tissue. Our previous studies indicated that decreasing visceral adipose tissue by surgical removal of the parametrial fat pads inhibited UVB-induced carcinogenesis in SKH-1 mice fed a HFD, but not a LFD indicating that the parametrial fat tissue from mice fed a HFD played a role in skin carcinogenesis. To understand how a HFD may influence the intrinsic properties of the parametrial fat tissue to influence UVB-induced skin tumor formation we investigated differences between HFD and LFD fat tissue in the expression of crown-like structures (CLS), the surrogate marker for dead adipocytes. CLS are indicated by an F4/80 macrophage stain to show resident macrophages that infiltrated to engulf necrotic adipose tissue. Mice fed a HFD for 4 months had more parametrial fat tissue (Figure 1A) that was characterized larger adipocytes and a higher density of CLS ( $88.8 \pm 8.0 \mathrm{~mm}^{2}$; dark brown stain) compared with mice fed a LFD $\left(0.9 \pm 0.2 \mathrm{~mm}^{2}\right.$; Figure 1B).

To determine if the presence of CLS was associated with adipokine expression, parametrial fat pads were isolated under sterile conditions from mice fed a HFD or LFD. The parametrial fat tissue was homogenized, and $500 \mu \mathrm{L}$ (approximately $0.5 \mathrm{~g}$ ) was placed in a 15 -mm wide insert with $0.4 \mu \mathrm{m}$ pores which permitted the diffusion of small molecules released from the fat tissue to pass through into the minimal essential medium (MEM; Figure 2A). The fat tissue

\section{A}

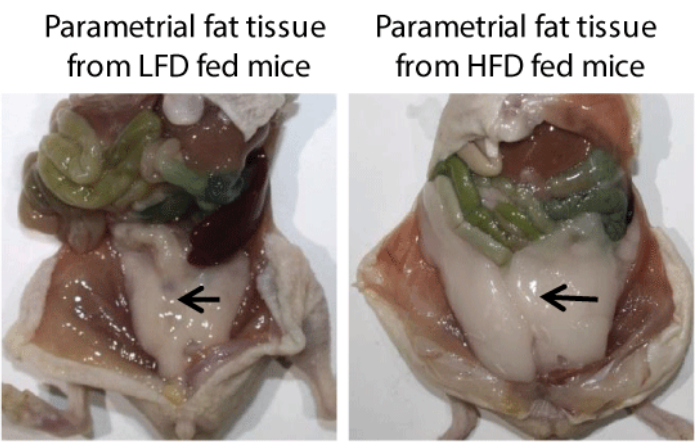

B

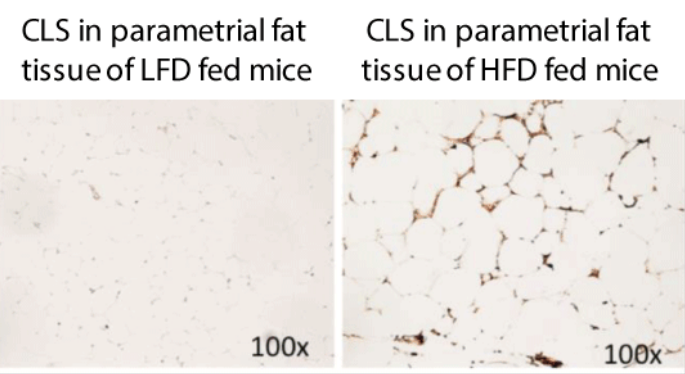

Figure 1: Effect of high fat diet feeding on parametrial fat pad size and crownlike structure density. A. Picture demonstrating parametrial fat pad (fat tissue) size after 4 months of LFD or HFD feeding. B. Parametrial fat was fixed in formalin and immunohistochemically stained with F4/80 for CLS. Pictures were taken under $100 \mathrm{X}$ microscopic magnification with a light microscope and are representative of data obtained from more than three mice. Parametrial fat from mice fed a HFD demonstrated larger adipocytes and a higher density of CLS (88.8 $\pm 8.0 \mathrm{~mm}^{2}$; dark brown stain) compared with mice fed a LFD $\left(0.9 \pm 0.2 \mathrm{~mm}^{2}\right)$ homogenate in the insert was incubated at $37^{\circ} \mathrm{C}$ and the medium was collected hourly $(0-8 \mathrm{~h}$ ) for protein quantitation (Figure 2B). Protein levels increased over time and plateaued at $4 \mathrm{~h}$ (Figure 2B). Therefore, we collected the fortified medium of fat tissue filtrate at $4 \mathrm{~h}$ for experimental treatments. In addition, we found that more protein was filtrated into MEM from the fat tissue filtrate of mice fed a LFD than from mice fed a HFD (Figure 2B). Similar results were observed for non-homogenized fat tissue. Fat tissue filtrates from mice fed a HFD for 3-6 months demonstrated higher levels of adipokines compared with that from mice fed a LFD. Elevated amounts of monocyte chemo attractant protein-1 (MCP-1), interleukin-6 (IL-6), leptin, Serpin E1/ plasminogen activator inhibitor-1 (PAI-1) and intracellular adhesion molecule-1 (ICAM-1) were released from the parametrial fat tissue of mice fed a HFD compared with a LFD (Figure 2C). Of these elevated adipokines, only ICAM-1 was present in fat tissue filtrate of mice fed a LFD (Figure 2C).

Both macrophages and adipokines have been shown to cause the release of and stimulate the production of reactive oxygen species (ROS) from tissue, so we next looked at the effect of the fat tissue filtrate on the induction of ROS in JB6 cells. Cells were treated with TPA as a control because JB6 cell transformation by TPA is dependent on the generation of ROS [12]. Treatment of JB6 cells with fat tissue filtrate $(50 \mu \mathrm{g}$ protein $/ \mathrm{mL})$ from mice fed a LFD or HFD for 4 months resulted in a rapid increase in ROS as measured by DCF fluorescence starting as early as $1 \mathrm{~h}$ post-fat tissue filtrate treatment (Figure 2D). There was an approximate 50- and 80-fold increase, respectively, in the level of ROS in JB6 cells treated with fat pad filtrate from mice fed a LFD or HFD compared with cells treated with 5\% FBS at $8 \mathrm{~h}$ after treatment (time of peak response) (Figure 2D). ROS levels were $48 \%$ higher $\left.{ }^{* *} \mathrm{P}<0.01\right)$ at $8 \mathrm{~h}$ in JB6 cells treated with fat tissue filtrate from mice fed a LFD compared with a HFD (Figure 2D). ROS was still 10-fold higher in JB6 cells treated with fat tissue filtrate from mice fed a LFD or HFD compared with cells treated with 5\% FBS at 24-48 h (Figure 2D). Treatment of JB6 cells with TPA $(10 \mathrm{ng} / \mathrm{mL})$ as a control resulted in a 25 - to 30 -fold increase in ROS at $4 \mathrm{~h}$ post-treatment (time of peak response), and ROS returned to control levels by $24-48 \mathrm{~h}$ post-treatment. TPA treatment in the absence of FBS stimulated ROS formation to a higher extent than the other treatments; however, this caused cell death (data not shown). In summary, the fat tissue filtrate from mice fed HFD was more active than fat tissue filtrate from mice fed the LFD, and TPA had the least activity for stimulating the formation of ROS.

Fat tissue filtrate from mice fed a high fat diet stimulates the proliferation of JB6 cells growing in liquid medium. JB6 cells were treated with fat tissue filtrate $(50 \mu \mathrm{g}$ protein $/ \mathrm{mL})$ in the absence of FBS or with 1 or $5 \%$ FBS as controls. Cell number was counted at 1,3,5, and 7 days of incubation. Fat tissue filtrate $(50 \mu \mathrm{g}$ protein $/ \mathrm{mL})$ from mice fed a HFD stimulated JB6 cell proliferation in the absence of serum to about the same extent as was observed for cells cultured with 5\% FBS (Figure 3A). To determine the dose response of the fat tissue filtrate, cells were treated with 25,50 and $100 \mu \mathrm{g}$ protein $/ \mathrm{mL}$ of the fat tissue filtrate or with $5 \%$ FBS as a control. After 7 days of treatment, cloning efficiency was measured by the number of well-separated Giemsa stained clones. Fat tissue filtrate from mice fed a LFD or HFD for 4 months dose-dependently increased the number of JB6 clones (Figure 3B). Cloning efficiency was increased by $166 \%$ with $25 \mu \mathrm{g}$ protein $/ \mathrm{mL}$, by $50 \%$ with $50 \mu \mathrm{g}$ protein $/ \mathrm{mL}$, and by $29 \%$ with $100 \mu \mathrm{g}$ protein $/ \mathrm{mL}$ of fat pad filtrate from mice fed a HFD compared with fat pad filtrate from mice fed a LFD $\left({ }^{*} \mathrm{P}<0.05\right.$, Figure $\left.3 \mathrm{~B}\right)$.

Fat tissue filtrate from mice fed a high fat diet stimulates the 
Citation: Bernard JJ, Lou YR, Peng QY, Li T, Vakil PR, et al. (2014) Parametrial Fat Tissue from High Fat Diet-Treated SKH-1 Mice Stimulates Transformation of Mouse Epidermal JB6 Cells. J Carcinog Mutagen 5: 183. doi:10.4172/2157-2518.1000183
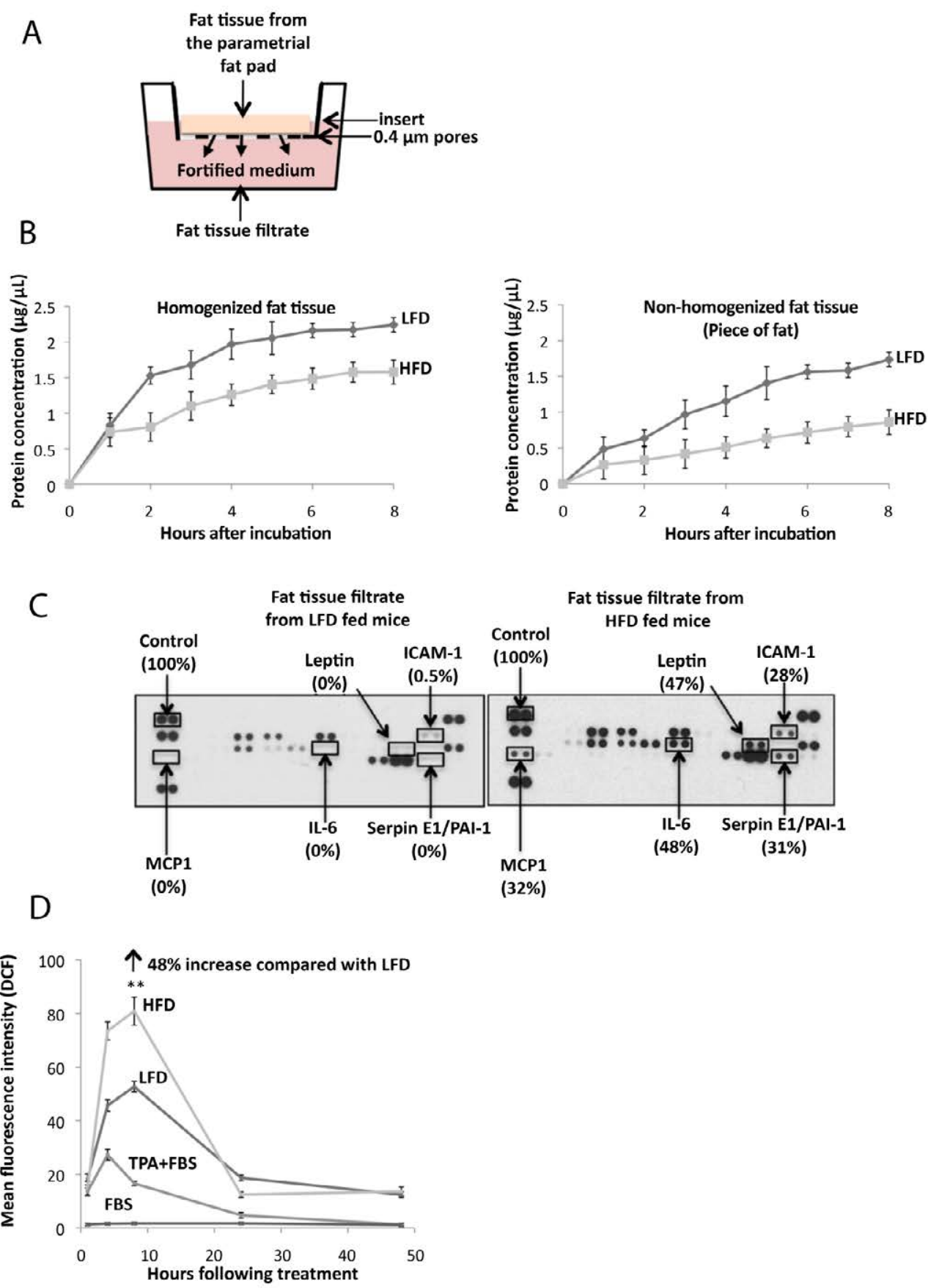

Figure 2: Effect of high fat diet feeding on adipokine production and reactive oxygen species stimulation. A. Parametrial fat pad homogenate (0.5 g fat) from female SKH-1 mice that had been fed a $60 \%$ kcal high fat diet (HFD) or low fat chow diet (LFD) for 4 months was placed in $1.0 \mathrm{~mL}$ of MEM on a hanging well insert. Cytokines and other fat constituents passed through a polyethylene terephthalate membrane with $0.4 \mu \mathrm{m}$ pores in the insert for 4 hours to provide fat tissue filtrate in MEM. B. Fat was isolated and fat tissue filtrate was made as described in (A). Graph demonstrates the amount of protein in MEM following culture with parametrial fat tissue homogenate or parametrial fat pad secretions from an intact piece of fat. C. Elevated amounts of monocyte chemoattractant protein-1 (MCP-1), interleukin-6 (IL-6), leptin, Serpin E1/plasminogen activator inhibitor-1 (PAI-1) and intracellular adhesion molecule-1 (ICAM-1) were released from the parametrial fat of mice fed a HFD compared with a LFD. D. Mean fluorescence intensity of the 2', 7'-dichlorofluorescein (DCF) (excitation $488 \mathrm{~nm}$; fluorescence $530 \mathrm{~nm}$ ) +/- 15 of 5,000 events was measured. Fat tissue filtrate $(50 \mu \mathrm{g}$ protein $/ \mathrm{mL})$, or TPA $(10 \mathrm{ng} / \mathrm{mL})$ induced ROS in JB6 cells. HFD fat tissue filtrate treatment stimulated the formation of ROS $48 \%$ more than LFD fat tissue filtrate as measured by DCF fluorescence at 8 hours ${ }^{* *} P<0.01$. All data are mean $\pm S E M$, Student $t$ test (unpaired, two-tailed).

formation of a fibroblast-like morphology of JB6 cells growing in liquid medium. JB6 cells were plated at 100 cells per well in a 6-well plate and treated with fat tissue filtrate $(25-100 \mu \mathrm{g}$ protein/mL) from mice fed a HFD. Giemsa staining of JB6 cells after growing in liquid medium for 7 days showed clones that were characterized as either having an epithelial-like or a fibroblast-like morphology (Figure 4A and 4B). Exposure of JB6 cells to fat tissue filtrate from mice fed a HFD for 7 days increased the number of clones with a fibroblast-like morphology 
Citation: Bernard JJ, Lou YR, Peng QY, Li T, Vakil PR, et al. (2014) Parametrial Fat Tissue from High Fat Diet-Treated SKH-1 Mice Stimulates Transformation of Mouse Epidermal JB6 Cells. J Carcinog Mutagen 5: 183. doi:10.4172/2157-2518.1000183

A

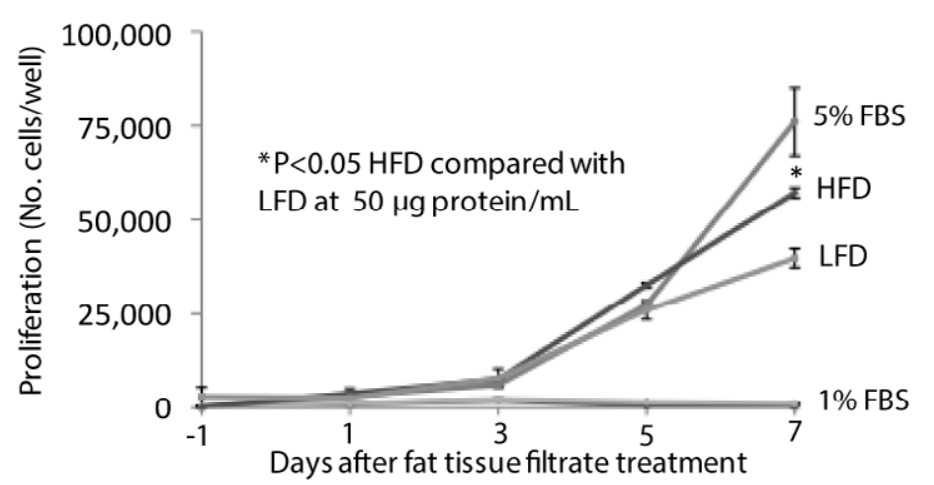

B

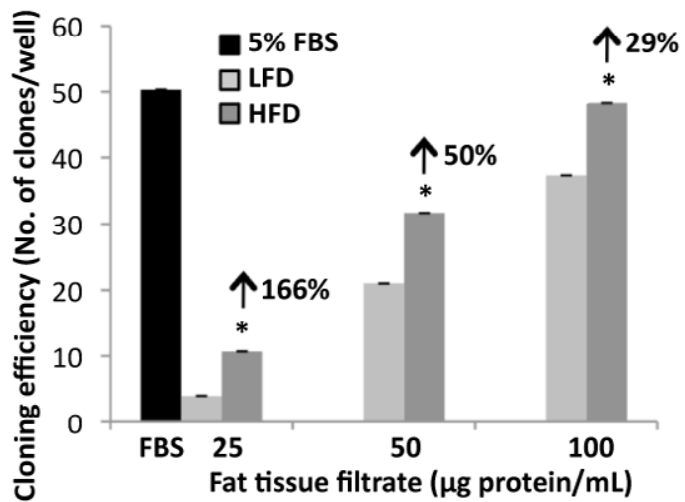

Figure 3: Fat tissue filtrate from mice fed a high fat diet stimulates the proliferation of JB6 cells growing in liquid medium. A. JB6 cells were treated with $1 \%$ FBS, $5 \%$ FBS or fat tissue filtrate $(50 \mu \mathrm{g}$ protein $/ \mathrm{mL})$ from mice fed a HFD for 4 months and were counted at $1,3,5$, and 7 days. The fat tissue filtrate from mice fed a HFD stimulated JB6 cell proliferation to about the same extent as 5\% FBS. One well $=9.6 \mathrm{~cm} 2$. B. JB6 cells were seeded at 100 cells per well in a 6 -well plate. Cells were treated with $5 \%$ FBS or fat tissue filtrate from mice fed a HFD for 7 days and stained with Giemsa. Cloning efficiency, as measured by the number of Giemsa-stained clones, was significantly increased to a greater extent in JB6 cells cultured with fat tissue filtrate from mice fed a HFD for 4 months compared with cells cultured with fat tissue filtrate from mice fed a LFD for 4 months $\left({ }^{*} \mathrm{P}<0.05\right)$. Arrows indicate $\%$ increase in cloning efficiency at the different doses. One well $=9.6 \mathrm{~cm} 2$. Data are mean \pm SEM, Student $t$ test (unpaired, two-tailed)

A
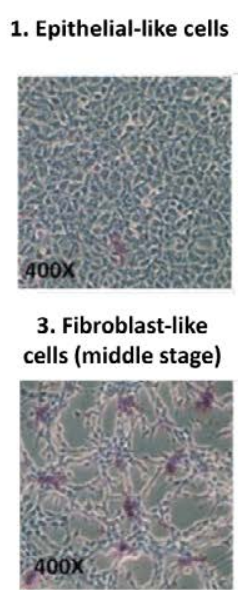

C
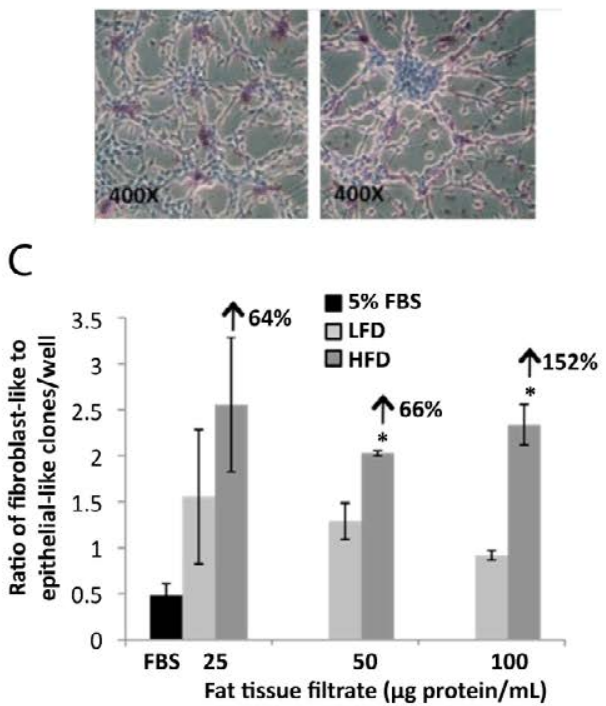

B 2. Fibroblast-like

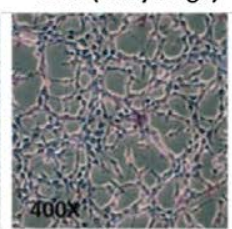

4. Fibroblast-like cells (late stage)

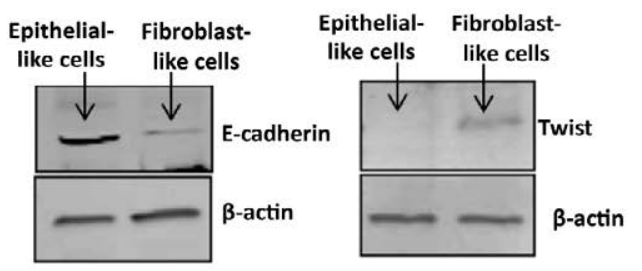


Citation: Bernard JJ, Lou YR, Peng QY, Li T, Vakil PR, et al. (2014) Parametrial Fat Tissue from High Fat Diet-Treated SKH-1 Mice Stimulates Transformation of Mouse Epidermal JB6 Cells. J Carcinog Mutagen 5: 183. doi:10.4172/2157-2518.1000183

(Figure 4A). Many of the fibroblast-like clones showed the piling up of cells suggestive of foci formation and the loss of contact dependent growth inhibition (Figure 4A), key features of transformed cells. The fibroblast-like clones pictured were characterized as being either early(A2), middle-(A3), or late-stage (A3) depending upon the size of the foci formed (Figure 4A). Morphological changes present in JB6 cells following exposure of the cells to fat tissue filtrate from mice fed a HFD were consistent with those associated with an epithelial-mesenchymal transition. Therefore we examined hallmark characteristics of this process and found that treatment of JB6 cells with fat tissue filtrate from mice fed a HFD resulted in the loss of E-cadherin and the induction of Twist, a transcriptional repressor of E-cadherin (Figure 4B). Our results suggest that treatment of JB6 cells with fat tissue filtrate from mice fed a HFD enhanced epithelial-mesenchymal transition.

The ratio of clones with fibroblast-like cells to clones with epitheliallike cells was increased in JB6 cells cultured with fat tissue filtrate from mice fed HFD or LFD when compared with JB6 cells cultured with 5\% FBS (Figure 4C). In addition, JB6 cells treated with fat tissue filtrate from mice fed the HFD had a greater ratio of clones with fibroblast-like morphology to epithelial-like morphology when compared with cells cultured with fat tissue filtrate from mice fed the LFD at 50 and $100 \mu \mathrm{g}$ protein $/ \mathrm{mL}$ by $66 \%$ and $152 \%\left({ }^{\star} \mathrm{P}<0.05\right.$, Figure $\left.4 \mathrm{C}\right)$. Although a similar difference was observed between the two groups when JB6 cells were treated with a lower concentration of fat tissue filtrate $(25 \mu \mathrm{g}$ protein/ $\mathrm{mL}$ ), the results were not statistically significant, which may be due to the low number of clones (Figure 4C). Overall, these data suggest that fat tissue filtrate from mice fed a HFD will stimulate the conversion from an epithelial to a mesenchymal phenotype to a greater extent than that from mice fed a LFD.

Fat tissue filtrate from mice fed a high fat diet stimulates the transformation of JB6 cells more than fat tissue filtrate from mice fed a low fat diet as measured by growth in soft agar. Following 7 days of treatment with fat tissue filtrate, JB6 cells were plated directly in soft agar for an anchorage independent colony formation assay. JB6 cells cultured with fat tissue filtrate formed more colonies in soft agar than cells cultured with 5\% FBS, and JB6 cells treated with fat tissue filtrate of mice fed HFD demonstrated the highest capacity to form colonies in soft agar (Figure 5A and 5B). Overall, fat tissue filtrate from mice fed the HFD stimulated colony formation in soft agar $160 \%$ more than fat pad filtrate from mice fed the LFD, and the colonies formed were larger (mostly greater than 32 cells; ${ }^{*} \mathrm{P}<0.05$, Figure $5 \mathrm{~A}$ and $5 \mathrm{~B}$ ). To determine if transformation of JB6 cells by fat pad filtrate was a reversible or irreversible process, transformed cells (colonies growing in soft agar) that were previously treated with a fat tissue filtrate in liquid medium were isolated from soft agar and grown for 16 passages (approximately 8 weeks) in 5\% FBS. After 16 passages in liquid medium, confluent cells were placed in soft agar for 14 days to determine colony formation and reversibility of the transformation. Stable transformation was observed since cells that grew in soft agar retained their ability to grow in soft agar after 16 passages with a similar cloning efficiency.

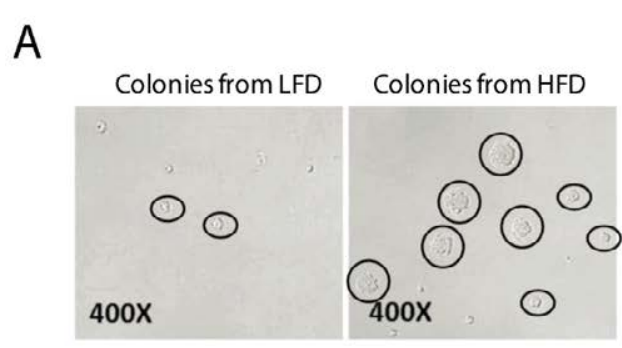

B

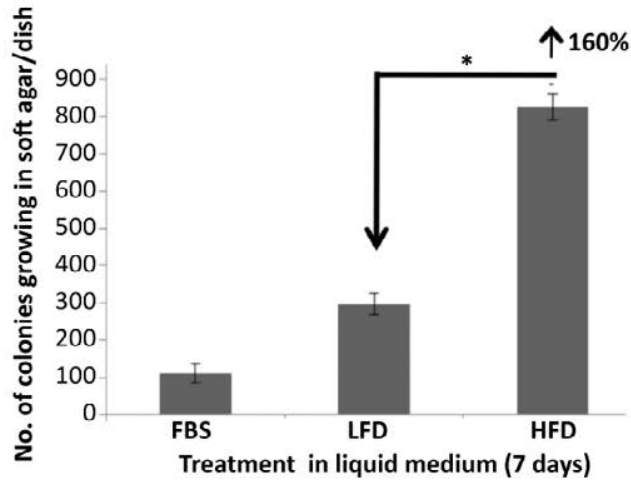

D

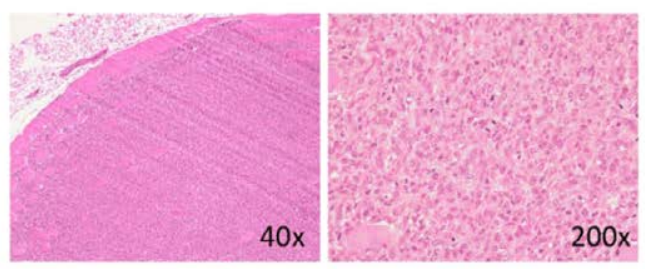

Figure 5: Fat tissue filtrate stimulates the transformation of JB6 cells. A. JB6 cells were treated with $5 \%$ FBS or fat tissue filtrate $(50 \mu \mathrm{g}$ protein/mL) for 7 days, and then 104 cells were placed in soft agar for 14 days. The picture shows JB6 cells growing in soft agar that were cultured with fat tissue filtrate from mice fed either LFD or HFD (magnification $=400 \mathrm{x}$ ). B. Cells were treated as described in $(\mathrm{A})$. Fat tissue filtrate from mice fed a HFD stimulated colony formation in soft agar $160 \%$ more than fat pad filtrate from mice fed a LFD $\left({ }^{*} P<0.05\right)$. Data was obtained from 3 separate clones per treatment group. One dish $=20 \mathrm{~cm}^{2}$. All data are mean \pm SEM, Student $t$ test (unpaired, two-tailed). C. Mice were injected with $2 \times 10^{6} \mathrm{JB} 6$ cells subcutaneously in the right and left flank of a SCID mouse. Mice were injected with cells treated with fat tissue filtrate as described in Figure 2. Data shows picture of tumor formation in SCID mice 10 days after injection. D. Immunohistochemistry of tumor in SCID mice injected with JB6 cells treated with HFD fat tissue filtrate demonstrates a fibrosarcoma at 40x and 200x magnification. 
To determine if transformed cells form tumors in mice, JB6 cells $\left(2 \times 10^{6}\right)$ treated with LFD or HFD fat pad filtrate were isolated and expanded from soft agar then injected subcutaneously into the left and right hind flanks of SCID mice. Tumor formation was analyzed at 10 days post injection. Only the cells transformed by HFD fat tissue filtrates formed tumors in mice (Figure 5C and 5D). Histopathology examination determined the formation of a type of fibroblastic sarcoma, which is a malignant mesenchymal tumor derived from fibrous connective tissue and characterized by the presence of immature proliferating fibroblasts or undifferentiated anaplastic spindle cells in a storiform pattern (Figure 5D). This tumor demonstrates invasion into muscle (Figure 5D).

\section{Discussion}

Diet-induced obesity is increasing globally [13]. It has been estimated that $68 \%$ of American adults are overweight or obese, causing significant morbidity and mortality [14]. Recent research suggests that obesity can influence cancer risk, survival and reoccurrence $[15,16]$. However, the molecular changes induced by obesity that actually enhance cancer development are poorly understood. Obese individuals generally consume more dietary fat, which has been linked to increased cancer risk [17]. Importantly, obese individuals have high amounts of adipose tissue, a metabolically active organ that, in addition to storing calories, secretes large numbers of adipokines $[18,19]$. Obesity alters the metabolic and endocrine functions of adipose tissue and is associated with elevated plasma free fatty acids [20] as well as proinflammatory adipokines/cytokines that may play a role in tumor development $[21,22]$. Several investigators have evaluated the relationship between dietary fat intake and non-melanoma skin cancer in both mice and humans. In mouse models, dietary lipid intake was shown to influence the risk of UVB-induced carcinogenesis [5,23]. Adele Green and colleagues reported in two separate prospective studies an association between high fat diets and human non-melanoma skin cancer risk $[2,3]$. Prior to this work, in an intervention clinical trial conducted by Homer Black and colleagues, patients with previous skin cancers who reduced their consumption of fat by $40 \%$ had significantly fewer skin cancers [24]. A recent prospective study indicated that obese individuals have a lower risk of developing non-melanoma skin cancers than individuals with normal body weight, but this may be due to the lack of sun exposure [25].

In our present study, we demonstrated that an aqueous filtrate made from parametrial fat pad homogenate (fat tissue filtrate) from mice fed a HFD stimulated the transformation of epidermal JB6 P+ (JB6) cells, suggesting a positive association between diet and skin cancer in an animal model. JB6 P+ cells are promotion competent (can be stimulated to grow in soft agar by phorbol ester tumor promoters such as TPA) as established by Nancy Colburn and her colleagues $[10,26]$ and confirmed in our laboratory (data not presented). Interestingly, the effects of fat tissue filtrate on cell transformation were greater in JB6 cells cultured with a fat tissue filtrate from mice fed a HFD compared with that from mice fed a LFD (Figure 5). These data correlate with our previous study that demonstrated that lipectomy surgery will reduce skin tumor formation in mice fed a HFD and not in mice fed a LFD [7]. Since the adipose tissue that regenerated in the lipectomized mice had fewer CLS and reduced adipokine expression [7], we hypothesized that macrophage infiltration into adipose tissue due to HFD-feeding would stimulate adipokine production, the formation of ROS and the transformation of keratinocytes.

Consistent with several recent reports [27-29], we demonstrated by $\mathrm{F} 4 / 80$ immunostaining that the parametrial fat tissue of mice fed a HFD had a higher density of CLS (Figure 1B). F4/80 is a wellcharacterized membrane protein that is used as a marker for mature mouse macrophages. CLS are surrogate markers for dead adipocytes and indicate tissue macrophage infiltration, suggesting a role for CLS in the pathogenesis of obesity and, potentially, a role in the transforming capacity of HFD fat pad filtrate. Further implicating CLS in cancer prognosis, Dannenberg and colleagues demonstrated that the presence of CLS as a predictive biomarker for post-menopausal breast cancer risk [30].

We demonstrated that HFD feeding stimulated the expression of adipokines such as intracellular adhesion molecule-1 (ICAM-1) and monocyte chemoattractant protein-1 (MCP-1) (Figure 2C). The induction of these proteins could potentially recruit macrophagesinto the parametrial adipose tissue. HFD feeding also stimulated the expression of IL-6, leptin and Serpin E1/ plasminogen activator inhibitor-1 (PAI1) (Figure 2C). Overall, these adipokines were either absent (MCP-1, IL-6, leptin, Serpin E1/PAI-1) or present in lower abundance (ICAM1) in the parametrial fat tissue of mice fed a LFD (Figure 2C). A prior report demonstrated that macrophages are responsible for at least 50\% of the IL- 6 production in adipose tissue [31] and IL-6 was shown to be a potent JB6 cell tumor promoter by stimulating growth in soft agar [26], suggesting that macrophages could play a role in the transforming capacity of HFD fat tissue filtrate. MCP-1, leptin, ICAM-1, and IL-6 have all been shown to inhibit apoptosis and stimulate proliferation in a wide range of cell types [32-34] and levels are elevated in obesity and in some cancers [35-38]. Serpin E1 has been shown to influence cell migration by interacting with vitronectin [39], cell surface receptors and regulating extracellular matrix proteolysis [40] and stimulate proliferation and survival by initiating several pathways such as MYC, $\mathrm{AKT}$, and NF- $\mathrm{KB}$ [41]. Interestingly, our previously published study demonstrated that feeding mice a HFD for 2 weeks, increased the level of Serpin E1, in the serum and the epidermis, and this increase was inhibited by the removal of the parametrial fat tissue, suggesting that this adipokine may be important for obesity-promoted skin cancer [7]. Future studies will utilize neutralizing antibodies, inhibitors, and receptor antagonists to determine the role of each of these adipokines in JB6 cell transformation by HFD fat tissue filtrate.

Macrophage infiltration into parametrial adipose tissue could also stimulate the production of ROS. Fat tissue filtrate from mice fed a HFD had a greater capacity to stimulate the formation of ROS per mg protein when compared to that from mice fed a LFD (Figure 2D). Several studies have implicated the balance between ROS and antioxidants in different stages of skin carcinogenesis. Colburn and colleagues have demonstrated that ROS, specifically superoxide production, is a key molecular mechanism of TPA-induced transformation of JB6 cells [12]. ROS can stimulate pathways that promote sustained cell proliferation, inhibit cell apoptosis and promote tumor progression and have also been shown to trigger the formation of downstream molecules involved in the process of EMT (reviewed in Wang et al. [42]). Interestingly, we demonstrated that fat tissue filtrate from mice fed a HFD can stimulate changes in cell morphology (Figure 4) characteristic of an epithelialmesenchymal transition (EMT), a developmental process characterized by the loss of epithelial markers and gain of mesenchymal markers that increase the ability of cells to migrate or invade [43-46]. Treatment of JB6 cells with fat tissue filtrate from mice fed a HFD stimulated the loss of E-cadherin, a hallmark of EMT, and increased the level of Twist, a key E-cadherin transcriptional repressor [44] (Figure 4B). Cells were seeded and adhered with an epithelial phenotype, but after several cell divisions converted to more fibroblast-like cells. These results suggested 
Citation: Bernard JJ, Lou YR, Peng QY, Li T, Vakil PR, et al. (2014) Parametrial Fat Tissue from High Fat Diet-Treated SKH-1 Mice Stimulates Transformation of Mouse Epidermal JB6 Cells. J Carcinog Mutagen 5: 183. doi:10.4172/2157-2518.1000183

that the morphological changes observed required proliferation. Although 5\% FBS stimulated cell proliferation to the same extent as fat tissue filtrate from mice fed a HFD (Figure 3), there was no appreciable effect on cell transformation, indicating that although proliferation may be required for transformation, it is not sufficient. Which specific reactive oxygen and nitrogen species are produced in JB6 cells and the role of ROS and antioxidants in fat tissue filtrate-induced proliferation and transformation is unknown, but will be the subject of future studies.

It was of considerable interest that JB6 cells that had a fibroblast-like morphology after culturing with fat tissue filtrate from mice fed a HFD proliferated in soft agar and formed tumors when injected into SCID mice (Figure 5). It was previously established that JB6 cells with a more fibroblastic-like phenotype form greater numbers of and larger colonies in soft agar compared with JB6 cells with a round epithelial shape [46]. These observations indicate that cells with a fibroblast-like morphology (after only 7 days of exposure to a fat tissue filtrate) are transformed as indicated by their growth in soft agar. Colonies isolated from soft agar retained their fibroblast-like morphology when grown for 16 passages in liquid medium and demonstrated the same colony forming efficiency. Continual observation of the fat tissue filtrate-transformed fibroblast-like cells and periodic testing of their ability to grow in soft agar demonstrated an irreversibility of transformation. These data are in contrast to a previous study with JB6 cells that demonstrated that TPA-induced morphological changes in JB6 cells were reversible [46]. However, in these studies the experimental conditions were different and a subpopulation of cells still demonstrated anchorage independence, suggesting partial stability of a transformed phenotype [46].

The model described in the present manuscript provides a foundation for future studies on molecular mechanisms by which parametrial fat tissue promotes skin cell transformation. Further research is needed to determine whether adipocytes and/ or inflammatory cells such as macrophages are the most critical contributors of adipokines and/or ROS that may be involved in the transforming capacity of the fat tissue filtrate from mice fed a HFD. It will also be of considerable interest to determine whether human fat tissue stimulates the transformation of JB6 cells or other immortalized cells such as those from the prostate, breast, colon, uterus, and kidneytissues that are prone to obesity-enhanced carcinogenesis [15]. Fat tissue filtrate-induced transformation of JB6 or other immortalized epithelial cells provides a useful in vitro model for studying molecular mechanisms of fat-induced tumor promotion as well as for evaluating the effects of potential chemopreventive agents.

In summary, parametrial fat tissue from animals fed a HFD had a higher density of macrophage-fused dead adipocytes (crown-like structures), more adipokines, and stimulated the production of more reactive oxygen species compared with parametrial fat tissue from mice fed a LFD. These differences between parametrial fat tissue from mice fed a HFD and LFD were associated with their effect on the in vitro transformation. Fat tissue filtrate made from the parametrial fat tissue of mice fed a HFD had $160 \%$ more transforming activity than that from mice fed a LFD and formed malignant mesenchymal tumors in vivo. These studies provide the first in vitro demonstration of a parametrial fat tissue-induced transformation of an epidermal cell.

\section{Grant Support}

K99CA177868 and R01CA128997, from the National Cancer Institute, Training Grant ES007148, Center Grant ES005022 from the
National Institute of Environmental Health Sciences (NIEHS), and funding from the Department of Chemical Biology.

\section{Author Contributions}

Y.-P.L., J.J.B. and A.H.C. designed research; J.J.B., Y.-P.L., Y.-R.L., Q.-Y.P., T.L., P.R.V., N.D. performed research; Y-.P.L., J.J.B. and A.H.C. analyzed data; Y.-P.L. J.J.B. and A.H.C. wrote the paper and Z.D. and J.D.L. helped design experiments and reviewed the manuscript.

\section{Reference}

1. Siegel R, Ward E, Brawley O, Jemal A (2011) Cancer statistics, 2011: the impact of eliminating socioeconomic and racial disparities on premature cancer deaths. CA Cancer J Clin 61: 212-236.

2. Ibiebele TI, van der Pols JC, Hughes MC, Marks GC, Green AC (2009) Dietary fat intake and risk of skin cancer: a prospective study in Australian adults. Int J Cancer 125: 1678-1684.

3. Ibiebele TI, van der Pols JC, Hughes MC, Marks GC, Williams GM, et al. (2007) Dietary pattern in association with squamous cell carcinoma of the skin: a prospective study. Am J Clin Nutr 85: 1401-1408.

4. Black HS (1998) Influence of dietary factors on actinically-induced skin cancer Mutat Res 422: 185-190.

5. Black HS, Lenger W, Phelps AW, Thornby JI (1983) Influence of dietary lipid upon ultraviolet-light carcinogenesis. Nutr Cancer 5: 59-68.

6. Lu YP, Lou YR, Lin Y, Shih WJ, Huang MT, et al. (2001) Inhibitory effects of orally administered green tea, black tea, and caffeine on skin carcinogenesis in mice previously treated with ultraviolet $B$ light (high-risk mice): relationship to decreased tissue fat. Cancer Res 61: 5002-5009.

7. Lu YP, Lou YR, Bernard JJ, Peng QY, Li T, et al. (2012) Surgical removal of the parametrial fat pads stimulates apoptosis and inhibits UVB-induced carcinogenesis in mice fed a high-fat diet. Proc Natl Acad Sci U S A 109: 90659070 .

8. Lu YP, Nolan B, Lou YR, Peng QY, Wagner GC, et al. (2007) Voluntary exercise together with oral caffeine markedly stimulates UVB light-induced apoptosis and decreases tissue fat in SKH-1 mice. Proc Natl Acad Sci U S A 104: 12936-12941.

9. Lu YP, Lou YR, Nolan B, Peng QY, Xie JG, et al. (2006) Stimulatory effect of voluntary exercise or fat removal (partial lipectomy) on apoptosis in the skin of UVB light-irradiated mice. Proc Natl Acad Sci U S A 103: 16301-16306.

10. Colburn NH, Former BF, Nelson KA, Yuspa SH (1979) Tumour promoter induces anchorage independence irreversibly. Nature 281: 589-591.

11. Warden $\mathrm{CH}$, Fisler JS (2008) Comparisons of diets used in animal models of high-fat feeding. Cell Metab 7: 277.

12. Nakamura Y, Colburn NH, Gindhart TD (1985) Role of reactive oxygen in tumor promotion: implication of superoxide anion in promotion of neoplastic transformation in JB-6 cells by TPA. Carcinogenesis 6: 229-235.

13. Finkelstein EA, Khavjou OA, Thompson H, Trogdon JG, Pan L, et al. (2012) Obesity and severe obesity forecasts through 2030. Am J Prev Med 42: 563570 .

14. Wang YC, McPherson K, Marsh T, Gortmaker SL, Brown M (2011) Health and economic burden of the projected obesity trends in the USA and the UK. Lancet 378: 815-825.

15. Calle EE, Rodriguez C, Walker-Thurmond K, Thun MJ (2003) Overweight obesity, and mortality from cancer in a prospectively studied cohort of U.S adults. N Engl J Med 348: 1625-1638.

16. Polednak AP (2008) Estimating the number of U.S. incident cancers attributable to obesity and the impact on temporal trends in incidence rates for obesityrelated cancers. Cancer Detect Prev 32: 190-199.

17. La Vecchia C (1992) Cancers associated with high-fat diets. J Natl Cancer Inst Monogr: 79-85.

18. Ouchi N, Kihara S, Funahashi T, Matsuzawa Y, Walsh K (2003) Obesity, adiponectin and vascular inflammatory disease. Curr Opin Lipidol 14: 561-566.

19. Berg KK, Madsen HO, Garred P, Wiseth R, Gunnes S, et al. (2009) The 
Citation: Bernard JJ, Lou YR, Peng QY, Li T, Vakil PR, et al. (2014) Parametrial Fat Tissue from High Fat Diet-Treated SKH-1 Mice Stimulates Transformation of Mouse Epidermal JB6 Cells. J Carcinog Mutagen 5: 183. doi:10.4172/2157-2518.1000183

additive contribution from inflammatory genetic markers on the severity of cardiovascular disease. Scand J Immunol 69: 36-42.

20. Kelley DE, Williams KV, Price JC, McKolanis TM, Goodpaster BH, et al. (2001) Plasma fatty acids, adiposity, and variance of skeletal muscle insulin resistance in type 2 diabetes mellitus. J Clin Endocrinol Metab 86: 5412-5419.

21. Baillargeon J, Platz EA, Rose DP, Pollock BH, Ankerst DP, et al. (2006) Obesity, adipokines, and prostate cancer in a prospective population-based study. Cancer Epidemiol Biomarkers Prev 15: 1331-5.

22. Ogunwobi O, Mutungi G, Beales IL (2006) Leptin stimulates proliferation and inhibits apoptosis in Barrett's esophageal adenocarcinoma cells by cyclooxygenase-2-dependent, prostaglandin-E2-mediated transactivation of the epidermal growth factor receptor and c-Jun NH2-terminal kinase activation. Endocrinology 147: 4505-4516.

23. Black HS (1987) Photocarcinogenesis and diet. Fed Proc 46: 1901-1905.

24. Jaax S, Scott LW, Wolf JE Jr, Thornby JI, Black HS (1997) General guidelines for a low-fat diet effective in the management and prevention of nonmelanoma skin cancer. Nutr Cancer 27: 150-156.

25. Pothiawala S, Qureshi AA, Li Y, Han J (2012) Obesity and the incidence of skin cancer in US Caucasians. Cancer Causes Control 23: 717-726.

26. Yu CY, Wang L, Khaletskiy A, Farrar WL, Larner A, et al. (2002) STAT3 activation is required for interleukin-6 induced transformation in tumorpromotion sensitive mouse skin epithelial cells. Oncogene 21: 3949-3960.

27. Cinti S, Mitchell G, Barbatelli G, Murano I, Ceresi E, et al. (2005) Adipocyte death defines macrophage localization and function in adipose tissue of obese mice and humans. J Lipid Res 46: 2347-2355.

28. Murano I, Barbatelli G, Parisani V, Latini C, Muzzonigro G, et al. (2008) Dead adipocytes, detected as crown-like structures, are prevalent in visceral fat depots of genetically obese mice. J Lipid Res 49: 1562-1568.

29. Strissel KJ, Stancheva Z, Miyoshi H, Perfield JW 2nd, DeFuria J, et al. (2007) Adipocyte death, adipose tissue remodeling, and obesity complications. Diabetes 56: 2910-2918.

30. Subbaramaiah K, Howe LR, Bhardwaj P, Du B, Gravaghi C, et al. (2011) Obesity is associated with inflammation and elevated aromatase expression in the mouse mammary gland. Cancer Prev Res (Phila) 4: 329-346.

31. Weisberg SP, McCann D, Desai M, Rosenbaum M, Leibel RL, et al. (2003) Obesity is associated with macrophage accumulation in adipose tissue. $\mathrm{J}$ Clin Invest 112: 1796-1808.

32. Shi $\mathrm{CL}$, Yu CH, Zhang $\mathrm{Y}$, Zhao D, Chang $\mathrm{XH}$, et al. (2011) Monocyte chemoattractant protein-1 modulates invasion and apoptosis of $\mathrm{PC}-3 \mathrm{M}$ prostate cancer cells via regulating expression of VEGF, MMP9 and caspase-3. Asian Pac J Cancer Prev 12: 555-559.
33. Heinrich PC, Behrmann I, Haan S, Hermanns HM, Müller-Newen G, et al. (2003) Principles of interleukin (IL)-6-type cytokine signalling and its regulation. Biochem J 374: 1-20.

34. Vyth-Dreese FA, Dellemijn TA, Frijhoff A, van Kooyk Y, Figdor CG (1993) Role of LFA-1/ICAM-1 in interleukin-2-stimulated lymphocyte proliferation. Eur J Immunol 23: 3292-3299.

35. Sartipy P, Loskutoff DJ (2003) Monocyte chemoattractant protein 1 in obesity and insulin resistance. Proc Natl Acad Sci U S A 100: 7265-7270.

36. Park HS, Park JY, Yu R (2005) Relationship of obesity and visceral adiposity with serum concentrations of CRP, TNF-alpha and IL-6. Diabetes Res Clin Pract 69: 29-35.

37. Ramos EJ, Xu Y, Romanova I, Middleton F, Chen C, et al. (2003) Is obesity an inflammatory disease? Surgery 134: 329-335.

38. Cozen W, Gebregziabher M, Conti DV, Van Den Berg DJ, Coetzee GA, et al (2006) Interleukin-6-related genotypes, body mass index, and risk of multiple myeloma and plasmacytoma. Cancer Epidemiol Biomarkers Prev 15: 22852291.

39. Hurt EM, Chan K, Serrat MA, Thomas SB, Veenstra TD, et al. (2010) Identification of vitronectin as an extrinsic inducer of cancer stem cell differentiation and tumor formation. Stem Cells 28: 390-398.

40. Wilkins-Port CE, Ye Q, Mazurkiewicz JE, Higgins PJ (2009) TGF-beta1 + EGFinitiated invasive potential in transformed human keratinocytes is coupled to a plasmin/MMP-10/MMP-1-dependent collagen remodeling axis: role for PAI-1. Cancer Res 69: 4081-4091.

41. Czekay RP, Wilkins-Port CE, Higgins SP, Freytag J, Overstreet JM, et al. (2011) PAI-1: An Integrator of Cell Signaling and Migration. Int J Cell Biol 2011 562481.

42. Wang Z, Li Y, Sarkar FH (2010) Signaling mechanism(s) of reactive oxygen species in Epithelial-Mesenchymal Transition reminiscent of cancer stem cells in tumor progression. Curr Stem Cell Res Ther 5: 74-80.

43. Chaffer CL, Thompson EW, Williams ED (2007) Mesenchymal to epithelia transition in development and disease. Cells Tissues Organs 185: 7-19.

44. Lee JM, Dedhar S, Kalluri R, Thompson EW (2006) The epithelial-mesenchymal transition: new insights in signaling, development, and disease. J Cell Biol 172 973-981.

45. Thiery JP, Sleeman JP (2006) Complex networks orchestrate epithelialmesenchymal transitions. Nat Rev Mol Cell Biol 7: 131-42.

46. Takahashi K, Heine UI, Junker JL, Colburn NH, Rice JM (1986) Role of cytoskeleton changes and expression of the $\mathrm{H}$-ras oncogene during promotion of neoplastic transformation in mouse epidermal JB6 cells. Cancer Res 46: 5923-5932. 